\title{
BMJ Global Health The effect of paid maternity leave on early childhood growth in low-income and middle-income countries
}

\author{
Deepa Jahagirdar, ${ }^{1}$ Sam Harper, ${ }^{1,2}$ Jody Heymann, ${ }^{3}$ Hema Swaminathan, ${ }^{4}$ \\ Arnab Mukherji, ${ }^{4}$ Arijit Nandi ${ }^{2}$
}

To cite: Jahagirdar D, Harper S, Heymann J, et al. The effect of paid maternity leave on early childhood growth in lowincome and middle-income countries. BMJ Glob Health 2017;2:e000294. doi:10.1136/ bmjgh-2017-000294

- Additional material is published online only. To view please visit the journal online (http://dx.doi.org/10.1136/ bmjgh-2017-000294).

Received 20 January 2017 Revised 6 June 2017 Accepted 14 June 2017

\section{(a) CrossMark}

'Department of Epidemiology, Biostatistics and Occupational Health, McGill University, Montreal, Canada ${ }^{2}$ Department of Epidemiology, Biostatistics and Occupational Health, Institute for Health and Social Policy, McGill University, Montreal, Canada ${ }^{3}$ Fielding School of Public Health, University of California, Los Angeles, California, USA ${ }^{4}$ Indian Institute of Management Bangalore, Centre for Public Policy, Bangalore, India

Correspondence to

Arijit Nandi;

arijit.nandi@mcgill.ca

\section{ABSTRACT}

Background Despite recent improvements, low heightfor-age, a key indicator of inadequate child nutrition, is an ongoing public health issue in low-income and middleincome countries. Paid maternity leave has the potential to improve child nutrition, but few studies have estimated its impact.

Methods We used data from 583227 children younger than 5 years in 37 countries surveyed as part of the Demographic and Health Surveys (2000-2014) to compare the change in children's height-for-age $z$ score in five countries that increased their legislated duration of paid maternity leave (Uganda, Zambia, Zimbabwe, Bangladesh and Lesotho) relative to 32 other countries that did not. A quasiexperimental difference-in-difference design involving a linear regression of height-for-age z score on the number of weeks of legislated paid maternity leave was used. We included fixed effects for country and birth year to control for, respectively, fixed country characteristics and shared trends in height-for-age, and adjusted for time-varying covariates such as gross domestic product per capita and the female labour force participation rate.

Results The mean height-for-age $z$ scores in the pretreatment period were $-1.91(\mathrm{SD}=1.44)$ and -1.47 $(S D=1.57)$ in countries that did and did not change their policies, respectively. The scores increased in treated and control countries over time. A 1-month increase in legislated paid maternity leave was associated with a decrease of $0.08(95 \% \mathrm{Cl}-0.20$ to 0.04$)$ in child height-forage $z$ score. Sensitivity analyses did not support a robust association between paid maternity leave policies and height-for-age z score.

Conclusion We found little evidence that recent changes in legislated paid maternity leave have been sufficient to affect child height-for-age $z$ scores. The relatively short durations of leave, the potential for low coverage and the strong increasing trend in children's growth may explain our findings. Future studies considering longer durations or combined interventions may reveal further insight to support policy.

\section{INTRODUCTION}

In 2013, 161 million children under 5 years old were estimated to be stunted. ${ }^{1}$ Stunting refers to low height-for-age and is a key indicator of inadequate child nutrition used by the WHO.

\section{Key questions}

What is already known about this topic?

- Taking maternity leave has been previously associated with longer breastfeeding duration, better diet and caring practices, which may all benefit child growth.

- Access to longer paid maternity leave is also found to increase vaccinations and lower infant mortality.

- However, no study has assessed the effect of maternity leave policy on child nutrition, and on the policy potential to improve nutritional status generally.

\section{What are the new findings?}

- This study is the first, to our knowledge, to estimate the impact of an increase in the weeks of legislated paid maternity leave on children's nutritional outcomes.

- Among low-income and middle-income countries, our quasiexperimental study does not provide evidence that legislating an increase from an average of 8.6 to 14.0 additional weeks of paid leave has an effect on child growth.

Recommendations for policy

- Although our study did not find an effect, the evidence to date suggests that there are multiple pathways through which longer paid maternity leave could improve child nutrition outcomes.

- Future studies exploiting similar natural experiments based on policy changes, studying longer/greater coverage and the effects of multiple simultaneous interventions can provide a more comprehensive picture of the link between maternity leave and early childhood growth.

Young children suffering from poor growth due to inadequate nutrition (as measured by low height-for-age) may have negative short-term and long-term outcomes, including increased susceptibility to disease, lower school achievement and hindered long-term economic productivity. ${ }^{2-5}$ In contrast to wasting, or low weight-for-height, stunting is a result of cumulative malnutrition rather than fluctuations 
in weight associated with season or illness. ${ }^{6}$ That millions of children remain afflicted is of particular public health interest because inadequate height-for-age outcomes are largely preventable. ${ }^{7}$ Current evidence supports individual-level interventions towards this end, but the literature has remained sparse for population-level intervention, despite its potential effect on several pathways influencing child growth.

Interventions such as education and supplementation programme have shown promise to improve growth outcomes. Bhutta et $a l \mathrm{~s}^{8}$ review summarises support for interventions that influence child nutrition outcomes, including counselling to promote exclusive breast feeding until 6 months of age and dietary diversity beyond 6 months of age. Generally positive but inconsistent results also suggest that improved sanitation practices, nutrition education and nutrient supplementation interventions ${ }^{9-12}$ can improve child growth. While these types of interventions may be targeted or population-level, the latter have the potential for a broad impact on underlying barriers to improved health. For instance, removal of user fees to access health services increases coverage of child health interventions. ${ }^{13}$ However, the quantity and quality of evidence on specific policy strategies to improve child growth outcomes are low. ${ }^{8}$

Legislated paid maternity leave is another intervention with the potential to support better height-for-age outcomes, through several possible mechanisms. First, women with longer maternity leave are more likely to breast feed, ${ }^{14}$ leading to better growth outcomes. Up-to-date vaccinations ${ }^{15}$ and uptake of formal prenatal care $^{16}$ also may increase with paid maternity leave, and subsequently improve growth. Finally, women are more likely to keep their jobs if offered maternity leave benefits ${ }^{17}$ although the effect of the additional income on height-for-age $\mathrm{z}$ scores in low-income and middle-income countries to date is inconclusive. Maternity leave is thus acknowledged as a potentially important policy tool because it may enable many practices that improve height-for-age outcomes. ${ }^{18}$ However, in line with lack of evidence on policies for addressing child health, no study has directly assessed its effect on child malnutrition. ${ }^{8}$ In this study, we use cross-country variation in the timing of maternity leave policy changes to estimate its effect on child height-for-age $\mathrm{z}$ scores in low-income and middle-income countries.

\section{METHODS \\ Design}

Non-randomised population interventions such as policies that increase paid maternity leave are difficult to evaluate. The challenges relate to the lack of a control (or 'unexposed') group that is similar to an intervention (or 'exposed') group in all respects except for the intervention itself. Thus, any observed effect could be the result of particular characteristics of the exposed population, and/or other changes over time, rather than the intervention. To overcome these challenges, a difference-in-difference design is a useful approach to estimate a causal effect. Using this design, the changes in growth outcomes of children in treated (or exposed) countries before and after a legislated reform to their paid maternity leave policy are compared with corresponding changes among children in control (or unexposed) countries that did not reform their maternity leave policy. Assuming countries that did not change their policy are a credible control group, a difference-in-difference design enables estimation of a causal effect of paid maternity leave policy on child height-for-age z score.

\section{Sample}

Our sample was constructed from the Demographic and Health Surveys (DHS). These surveys use a two-stage cluster sampling design to collect comparable information on demographic, socioeconomic, nutritional, behavioural, fertility and health characteristics from a nationally representative sample of households in low-income and middle-income countries. Standardised tools, techniques and training of interviewers are used to ensure comparability of surveys across countries and survey waves. As part of the survey, information is collected on women of reproductive age (15-49 years), men (usually aged 15-54 or 15-59) and children 4 years of age and under. Further details regarding the DHS are available elsewhere. ${ }^{19}$ The Institutional Review Board of McGill University reviewed and approved this project.

Our sample consisted of 583227 children whose height and age were reported across 135 surveys from 37 DHS countries. The sampling frame included children under 5 years of age who were alive at the time of survey, and born between 1996 and 2014 (inclusive). This restriction was applied because the earliest maternity leave policy information was available for 1995 and the latest was available for 2013. We thus included all available surveys for year 2000 or later that collected information on child nutrition as earlier surveys included children born before 1996 (table 1). Of the 820473 live births across these surveys, 5507 occurred in 1995 as the children had not yet turned 5 at the time of interview in year 2000. These were excluded, leaving 814966 children born between 1996 and 2014 eligible for inclusion. A further 231769 (28\%) children were excluded from the main analysis because of implausible height values $(n=4376)$ or implausible age values $(n=143)$ based on WHO growth standards, ${ }^{20} 21$ missing height-for-age $\mathrm{z}$ score information $(\mathrm{n}=204799)$ or values 'flagged' by DHS $(\mathrm{n}=22421)$. As such, 583227 children were included in the final analysis (figure 1).

\section{Measures}

Our primary outcome was height-for-age $\mathrm{z}$ score. At the time of interview, height in centimetres and weight in kilograms are measured for all children in the household under the age of 5 . This information was converted to a z score based on the Child Growth Standards developed by the WHO. The z score reflects the difference between 
Table 1 Sample description

\begin{tabular}{|c|c|c|c|c|c|c|}
\hline Country & $\begin{array}{l}\text { DHS survey } \\
\text { years }\end{array}$ & $\begin{array}{l}\text { Birth years available } \\
\text { (minimum, maximum) }\end{array}$ & $\begin{array}{l}\text { Sample } \\
\text { size }\end{array}$ & $\begin{array}{l}\text { Mean HAZ* pre- } \\
2004\end{array}$ & $\begin{array}{l}\text { Mean HAZ* } \\
2004+\end{array}$ & $\begin{array}{l}\text { Mean maternity } \\
\text { leave (weeks) }\end{array}$ \\
\hline \multicolumn{7}{|c|}{ Control countries (countries without policy changes) } \\
\hline Armenia & $\begin{array}{l}2010,2005 \\
2000\end{array}$ & 1996, 2010 & 4034.0 & -0.8 & -0.7 & 20.0 \\
\hline Benin & $\begin{array}{l}2012,2006 \\
2011,2001\end{array}$ & 1996, 2012 & 23748.0 & -1.7 & -1.5 & 14.0 \\
\hline Bolivia & $\begin{array}{l}2003,2004 \\
2008\end{array}$ & 1998, 2008 & 16847.0 & -1.4 & -1.2 & 12.9 \\
\hline Burkina Faso & 2010,2003 & 1998, 2010 & 14633.0 & -1.6 & -1.4 & 14.0 \\
\hline Cambodia & $\begin{array}{l}2000,2005 \\
2010,2006 \\
2011\end{array}$ & 1996, 2010 & 8837.0 & -2.1 & -1.6 & 12.9 \\
\hline Cameroon & 2011, 2004 & 1999, 2011 & 8216.0 & -1.5 & -1.2 & 14.0 \\
\hline Colombia & $\begin{array}{l}2010,2004 \\
2009,2005 \\
2000\end{array}$ & 1996, 2010 & 32066.0 & -1.0 & -0.8 & 12.0 \\
\hline Congo & $\begin{array}{l}2005,2011 \\
2012\end{array}$ & 2000, 2012 & 8368.0 & -1.3 & -1.0 & 15.0 \\
\hline $\begin{array}{l}\text { Democratic } \\
\text { Republic of } \\
\text { Congo }\end{array}$ & $\begin{array}{l}2013,2014 \\
2007\end{array}$ & 2002, 2014 & 11324.0 & -2.2 & -1.6 & 14.0 \\
\hline $\begin{array}{l}\text { Dominican } \\
\text { Republic }\end{array}$ & $\begin{array}{l}2007,2013, \\
2002\end{array}$ & 1997, 2013 & 21735.0 & -0.6 & -0.4 & 12.0 \\
\hline Egypt & $\begin{array}{l}2008,2005 \\
2000\end{array}$ & 1996, 2008 & 30858.0 & -1.1 & -0.9 & 12.5 \\
\hline Ethiopia & $\begin{array}{l}2011,2000 \\
2005\end{array}$ & 1996, 2011 & 21504.0 & -2.1 & -1.5 & 12.9 \\
\hline Gabon & $\begin{array}{l}2012,2000 \\
2001\end{array}$ & 1996, 2012 & 6709.0 & -1.2 & -1.0 & 14.0 \\
\hline Ghana & 2008, 2003 & 1998, 2008 & 5467.0 & -1.4 & -1.1 & 12.0 \\
\hline Guinea & 2005, 2012 & 2000, 2012 & 5687.0 & -1.9 & -1.0 & 14.0 \\
\hline Haiti & $\begin{array}{l}2012,2006 \\
2005,2000\end{array}$ & 1996, 2012 & 11437.0 & -1.3 & -1.0 & 12.0 \\
\hline Honduras & $\begin{array}{l}2006,2012 \\
2011,2005\end{array}$ & 2000, 2012 & 19188.0 & -1.7 & -1.2 & 12.0 \\
\hline Jordan & $\begin{array}{l}2012,2007, \\
2002\end{array}$ & 1997, 2012 & 15554.0 & -0.7 & -0.5 & 10.0 \\
\hline Kenya & $\begin{array}{l}2009,2008, \\
2003\end{array}$ & 1998, 2009 & 9818.0 & -1.3 & -1.3 & 8.6 \\
\hline Liberia & $\begin{array}{l}2007,2013, \\
2006\end{array}$ & 2002,2013 & 7495.0 & -1.9 & -1.3 & 12.9 \\
\hline Madagascar & $\begin{array}{l}2009,2004 \\
2008,2003\end{array}$ & 1998, 2009 & 9295.0 & -1.9 & -1.8 & 14.0 \\
\hline Mali & $\begin{array}{l}2006,2013, \\
2012\end{array}$ & 2001, 2013 & 15091.0 & -1.8 & -1.3 & 14.0 \\
\hline Mozambique & $\begin{array}{l}2011,2003 \\
2004\end{array}$ & 1998, 2011 & 17369.0 & -1.8 & -1.6 & 8.6 \\
\hline Namibia & $\begin{array}{l}2000,2006 \\
2007\end{array}$ & 1996, 2007 & 6566.0 & -1.2 & -1.2 & 12.0 \\
\hline
\end{tabular}




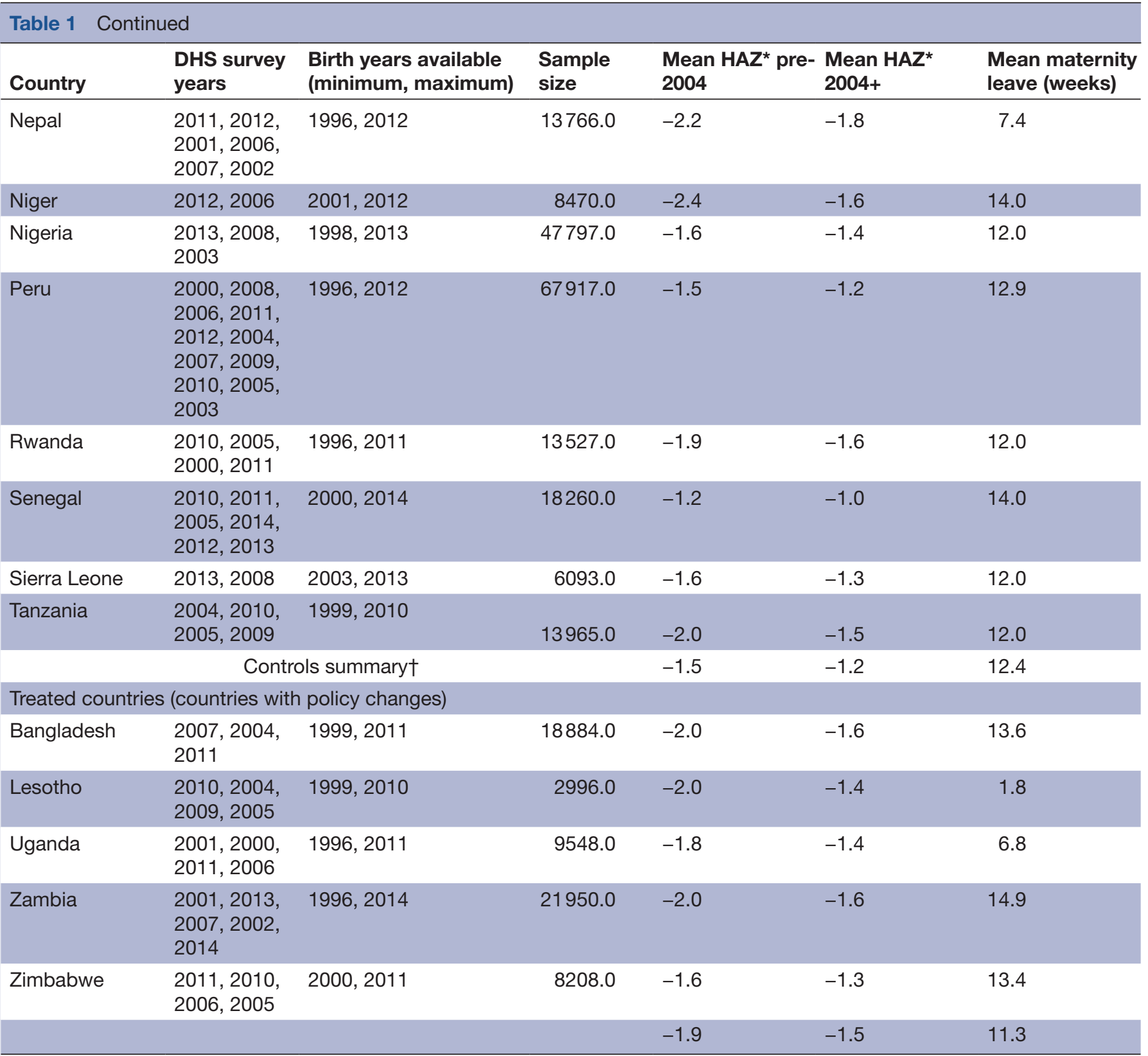

*Height-for-age z score.

†Means weighted by Demographic and Health Survey (DHS) weights.

the child's height and the average height in the reference population in terms of SD. The units thus represent shifts in the population distribution of heights. The respondent, usually the mother, is also asked to report the child's birth year and month.

The exposure of interest was the legislated length of paid maternity leave benefits in the year prior to the child's birth. Data on current maternity leave policies for each sampled country were provided by the University of California, Los Angeles' World Legal Rights Data Centre, and then collected retrospectively to 1995 by McGill University's Maternal and Child Health Equity research programme. It was not possible to distinguish between leaves that could be taken before and after the birth. Further details regarding the collection and coding of global maternity leave policies are available elsewhere. ${ }^{22}$

Countries that were found to have reformed their maternity leave policies between 1995 and 2013 were considered 'treated' countries (figure 2). These included Uganda, Zambia, Zimbabwe, Bangladesh and Lesotho. The 'control' countries were those that had at least two DHS surveys, but no maternity leave policy reform over the same time period (1995-2013). Malawi was excluded from the analysis because it changed policy the same year as its DHS survey was conducted, leaving the potential for exposure misclassification. The controls included 32 low-income and middle-income countries, as presented in table 1. 


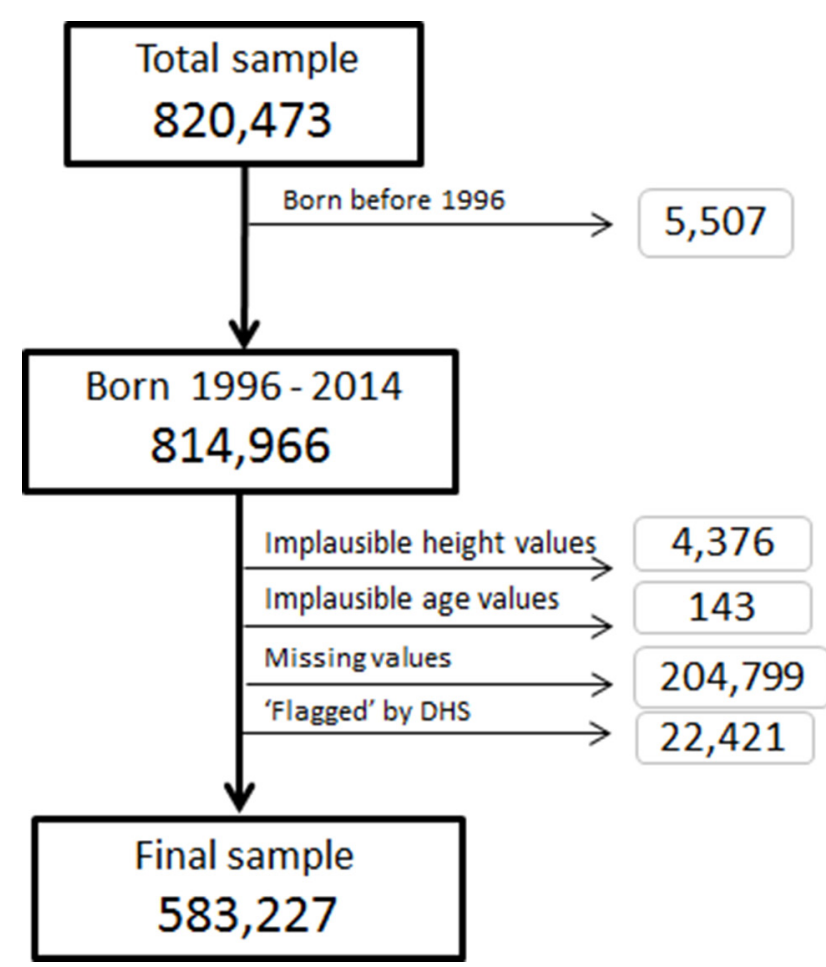

Figure 1 Sample size and exclusions. DHS, Demographic and Health Surveys.

We included predictors that had the potential to influence our exposure of paid maternity leave and affect children's height-for-age z scores. These characteristics were identified through a literature review. At the individual level, children's height-for-age z scores have been associated with maternal age at pregnancy, ${ }^{8}$ maternal height, ${ }^{23}$ family size and birth order. ${ }^{24}$ Maternal education, rural versus urban residence and household wealth quintiles are also associated with children's height-for-age. ${ }^{23}$ Additionally, we adjusted for birth month because the season may influence subsequent height-for-age $\mathrm{z}$ scores. The DHS contains information on these variables, and details are available in table 2.

At the country level, gross domestic product (GDP) per capita based on purchasing power parity, female labour force participation among women aged 15-64, total health expenditure (as a \% GDP), per cent living in an urban environment, government effectiveness rating and per capita government health expenditure based on purchasing power parity may also be associated with countries' decisions to increase maternity leave, and child growth outcomes. These variables were extracted from World Bank's World Development Indicators and Global Development Finance databases..$^{25}$ All the variables used constant 2011 dollars. Per capita government health expenditure and total health expenditure as a per cent of GDP were not available for Zimbabwe so this country was excluded from the fully adjusted model, model 3 . Trends in country characteristics are available in table 3 .

\section{Statistical analyses}

All analyses were completed in Stata V.13 and RStudio V.0.99.902 (RStudio Team, 2015, Integrated Development for R. RStudio, Boston, Massachusetts, USA). The full Stata code used to conduct the main analyses is available in online supplementary file 1: information document.

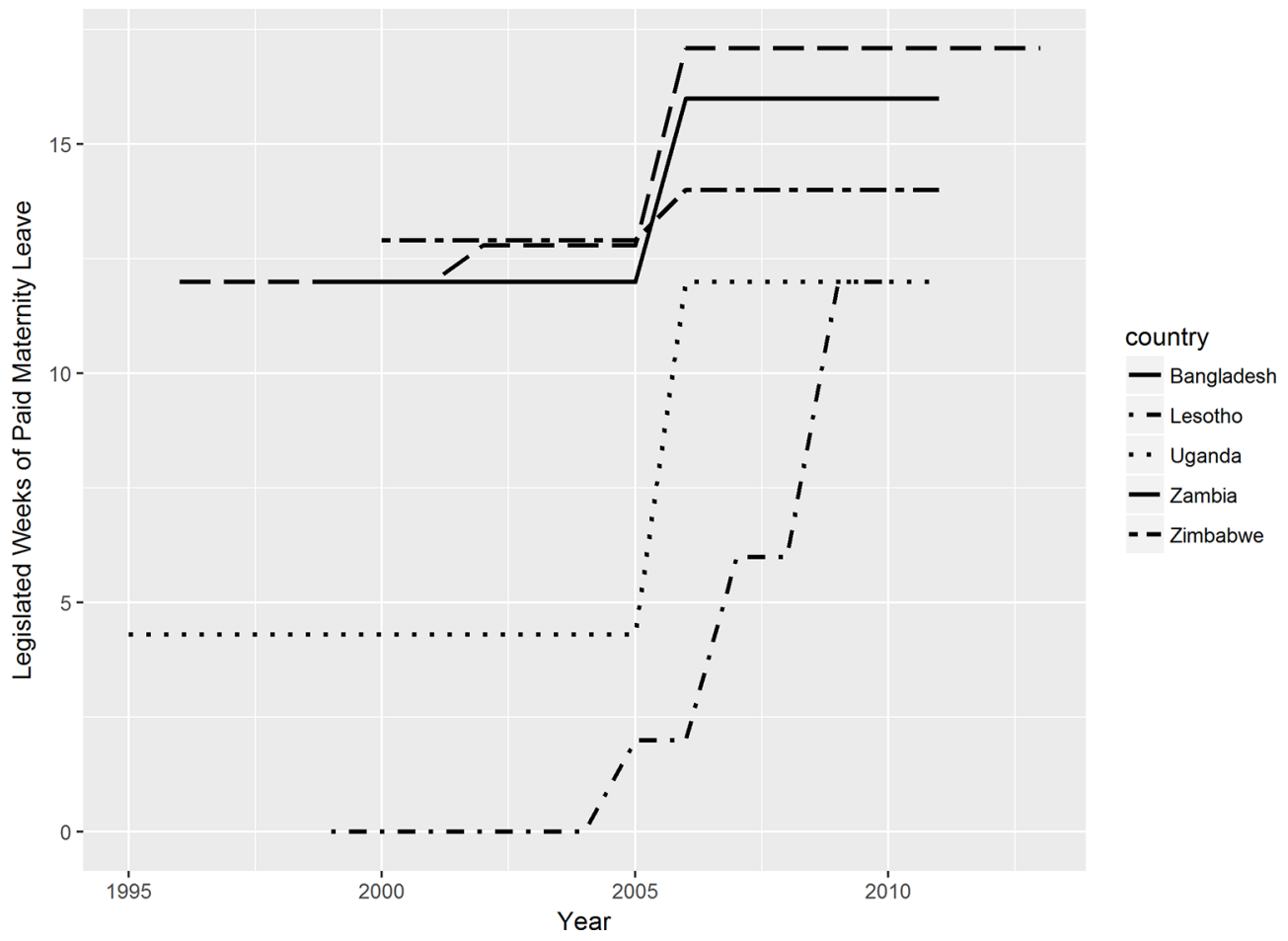

Figure 2 Legislated maternity leave duration in countries that changed policies. 
Table 2 Variables obtained from demographic and health surveys

\begin{tabular}{|c|c|}
\hline Variable & Description \\
\hline \multicolumn{2}{|l|}{ Primary outcome } \\
\hline Height-for-age z score & $\begin{array}{l}\text { Height in centimetres divided by weight in kilograms, } \\
\text { converted to a z score }\end{array}$ \\
\hline \multicolumn{2}{|c|}{ Explanatory variables: pregnancy/birth history } \\
\hline Maternal age at pregnancy & Logged maternal age in years at the time of childbirth \\
\hline Maternal height & Maternal height in centimetres \\
\hline Birth order number & Number indicating order in which children were born \\
\hline Family size & Number of household members listed \\
\hline Birth month & Value 1-4 indicating groups of 3 months (eg, $1=$ January March) \\
\hline \multicolumn{2}{|c|}{ Explanatory variables: sociodemographic } \\
\hline Maternal education & $\begin{array}{l}\text { Literacy: indicator based on interviewer observation of } \\
\text { mother's ability to write a sentence and/or attended primary } \\
\text { schooling }\end{array}$ \\
\hline Rural/urban residence & Indicator for urban versus rural residence \\
\hline Household wealth & $\begin{array}{l}\text { Quintile indicator based on composite index of asset } \\
\text { ownership, that is, electricity, radio, television, refrigerator, } \\
\text { bicycle, scooter, } \operatorname{car}^{39} 40\end{array}$ \\
\hline
\end{tabular}

\section{Examination of pretreatment trends}

Our difference-in-difference design provides an unbiased estimate of the effect of paid maternity leave policies on height-for-age $\mathrm{z}$ score under the strong assumption that control countries represent the counterfactual postpolicy trend in treated countries had they not reformed their maternity leave policies (ie, assumption of 'parallel trends'). We examined whether this assumption was tenable by comparing trends in the distributions of our outcome and potential confounders in the period before 2004, the first year that the treated countries adopted a policy change. To compare the pretreatment trends, we employed both visual and statistical testing methods. First, we plotted the annual mean height-for-age z scores in treated versus control countries. Second, we used linear regression models to assess whether there was heterogeneity in the pretreatment height-for-age trends (ie, before 2004) for countries that did versus did not change their maternity leave policy.

\section{Estimating the impact of maternity leave policies}

For child $i$ born in year $t$ in country $c$, we estimated the effect of a 1-month increase in the duration of paid maternity leave, $M_{t c}$, on the height-for-age z score, $Y_{i t c}$. We ran a series of nested multivariable linear regression models:

$$
\begin{gathered}
Y_{i t c}=\alpha+\beta^{*} M_{t c}+\lambda_{c}+\partial_{t}+\epsilon_{i t c} \\
Y_{i t c}=\alpha+\beta^{*} M_{t c}+\sum \beta^{*} X_{i t c}+\lambda_{c}+\partial_{t}+\epsilon_{i t c} \\
Y_{i t c}=\alpha+\beta^{*} M_{t c}+\sum \beta^{*} X_{i t c}+\sum \beta^{*} L_{t c}+\lambda_{c}+\partial_{t}+\epsilon_{i t c}
\end{gathered}
$$

In the first model, we included fixed effects for country $\left(\lambda_{c}\right)$ and birth year $\left(\partial_{t}\right)$ to account for, respectively, unobserved time-invariant confounders that vary across countries, and any temporal trends in the height-for-age $\mathrm{z}$ score that are shared across countries. In model 2, we added controls for measured individual/household-level characteristics, represented by the vector $X_{i t c}$. In model 3 , we added controls for measured country-level confounders, denoted by the vector $L_{t c}$.

All analyses incorporated robust SEs to account for clustering at the country level, and included respondent-level sampling weights to account for individual survey sample designs. The appropriate weights were calculated as per DHS guidelines, using information on the number of women aged 15-49 in each survey year from the Population Division of the United Nations. ${ }^{26}$ We applied the denormalisation of standard weights approach described in the DHS Sampling and Household Listing Manual. ${ }^{27}$

\section{Sensitivity analysis}

We examined the robustness of our main findings through sensitivity analyses that involved modifying the exposure, outcome and inclusion criteria. With regard to the exposure, we assessed 'lead' and 'lag' effects, and used full-time equivalent (FTE) months of maternity leave. The first involved running additional models where the exposure was assigned as the maternity leave duration legislated in years after, and before, the child's birth. Assessing lead and lag effects can provide further support for the robustness of any observed effect because they indicate whether the policy effect persisted beyond the year of implementation, or whether any policy effect can be observed before the actual year of implementation. The second sensitivity analysis involved using the number of weeks of FTE maternity leave as our main exposure rather than absolute weeks of maternity leave to account for the wage replacement rate. The FTE variable was derived as the number of weeks of maternity leave multiplied by the wage replacement rate. With regard to the outcome, we ran additional models with the outcome 


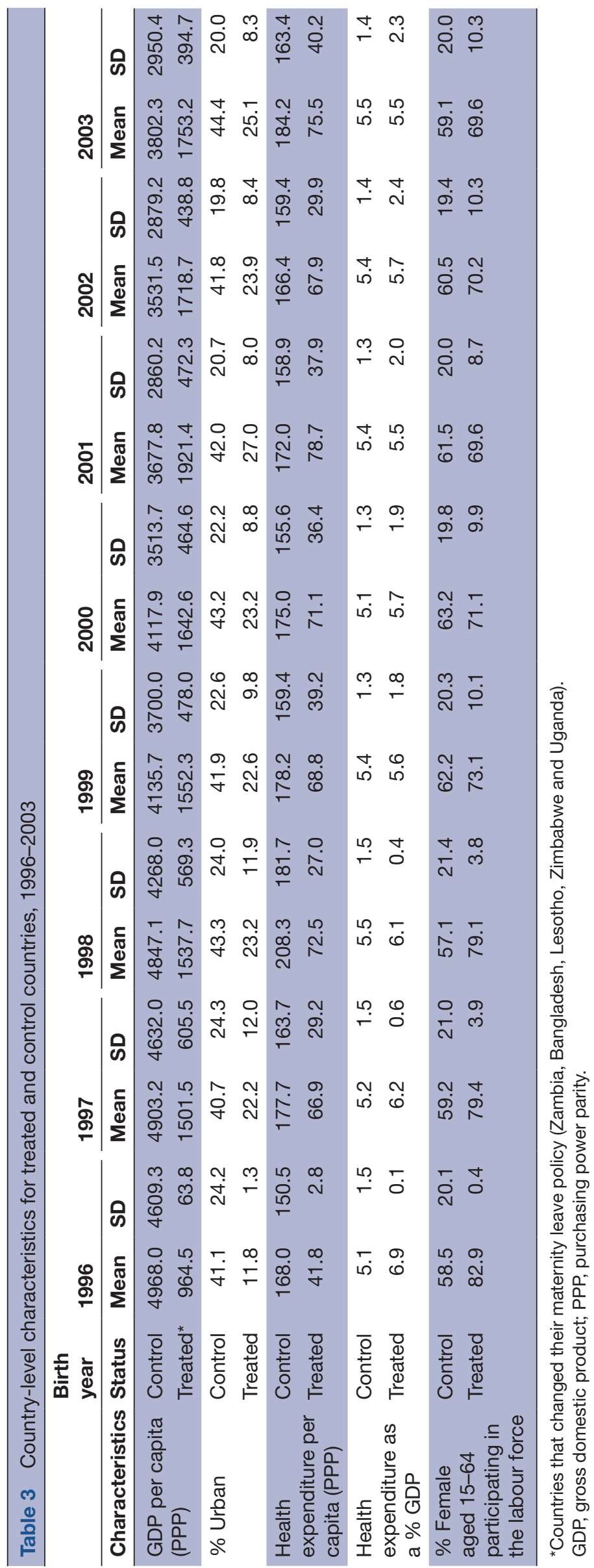




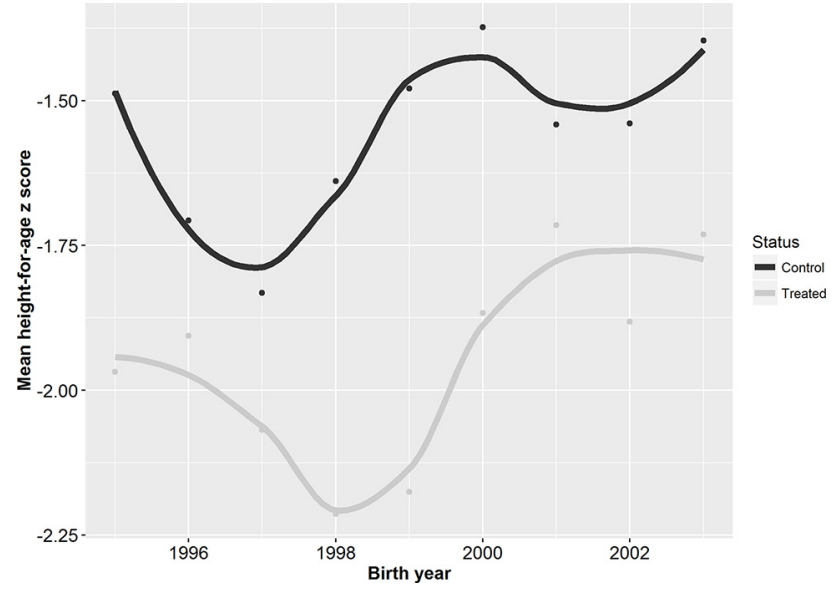

Figure 3 Trends in mean height-for-age z scores in control versus treated countries before the first year of maternity leave policy changes in 2004.

measured by a binary stunting indicator (height-for-age $\mathrm{z}$ score $<-2)$ rather than a continuous score, and restricting analyses to children who were under 3 years.

\section{RESULTS}

\section{Sample description}

The mean legislated paid maternity leave duration in control countries was 12.4 weeks $(\mathrm{SD}=1.82)$, although the value ranged from 7.4 to 20 weeks. Between 1995 and 2013, maternity leave policies changed in five countries. These were considered the 'treated countries' (figure 1). In countries that changed their policies, the mean duration of legislated paid maternity leave prior to year 2004 was 8.6 weeks $(\mathrm{SD}=4.5)$. After 2004 , the mean duration increased to 14.0 weeks $(\mathrm{SD}=3.7)$ (figure 1$)$.

\section{Examination of pretreatment trends}

The weighted mean height-for-age $\mathrm{z}$ score in the pretreatment period was $-1.47(\mathrm{SD}=1.57)$ in control countries compared with -1.91 ( $\mathrm{SD}=1.44)$ in treated countries (ie, countries that changed their policies). Although there was a strong increasing trend in height-for-age $\mathrm{z}$ scores in treated and control countries over time, our descriptive analyses showed that this trend did not differ based on treatment status prior to maternity leave policy changes (figure 3). An F-test for the joint significance of the effect of treatment status and birth year on the height-for-age $\mathrm{z}$ score in the pretreatment period suggested some heterogeneity $(\mathrm{p}<0.00)$, but $\mathrm{p}$ values for the coefficients for the treatment status and birth year interaction term ranged from 0.22 to 0.93 , depending on the year. Overall we did not find strong evidence that trends in height-for-age $\mathrm{z}$ scores differed between treated and control countries before the maternity leave policy changes.

\section{Estimating the impact of maternity leave policies}

After 2004 the weighted mean height-for-age $\mathrm{z}$ score increased to $-1.21(\mathrm{SD}=1.68)$ in control countries and to $-1.50(\mathrm{SD}=1.56)$ in treated countries, representing a

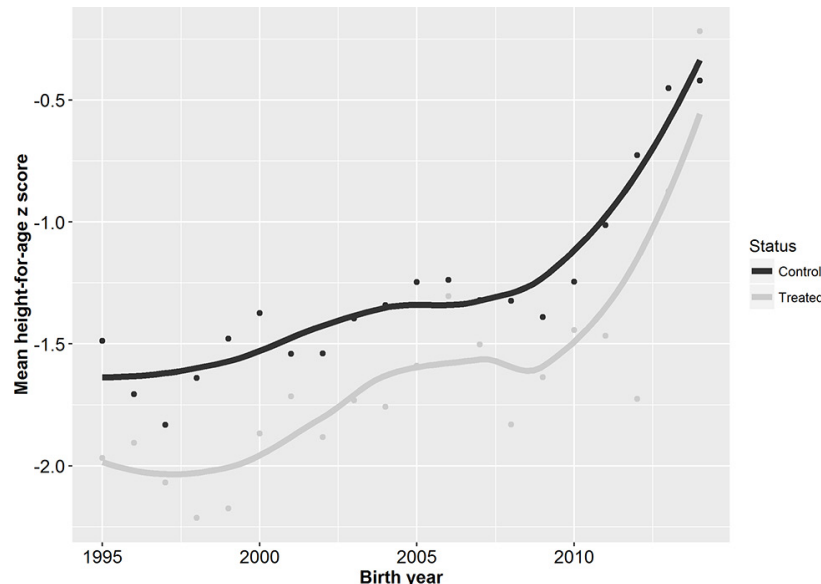

Figure 4 Long-term trend in mean height-for-age z scores 1995-2014 (with Loess smoother).

mean increase of 0.26 and 0.41 , respectively, with strong increasing trends up to 2013 in both groups (figure 4). In the model including only fixed effects for country and time trends (model 1), we found little impact of an additional month of legislated paid maternity leave on height-for-age $\mathrm{z}$ score $(\mathrm{B}=-0.04 ; 95 \% \mathrm{CI}-0.15$ to 0.06). The estimate became stronger in magnitude, but less precise, when we included individual (model 2) and time-varying country-level (model 3) predictors. The fully adjusted model estimated the mean heightfor-age $\mathrm{z}$ score to change by -0.08 (95\% CI -0.20 to 0.04 ) for each additional month of paid maternity leave (table 4).

\section{Sensitivity analysis}

The hypothesised lead and lag effects were not in a direction consistent with a robust policy effect. Our results also did not change when we restricted our sample to children under the age of 3 or used the number of FTE weeks of maternity leave as our main exposure (table 5). Additional post-hoc sensitivity analyses such as varying the control countries and allowing effect measure modification by baseline leave policy

Table 4 Main results from linear regression for the mean effect of a 1-month increase in legislated paid maternity leave on height-for-age $z$ score

\begin{tabular}{llll} 
& Model 1* & Model 2† & Model 3 \\
\hline Effect & -0.04 & -0.09 & -0.08 \\
estimate & $(-0.15$ to 0.06$)$ & $(-0.20$ to 0.02$)$ & $(-0.20$ to 0.04$)$ \\
$(95 \% \mathrm{Cl})$ & & & \\
\hline
\end{tabular}

*With fixed effects for country and birth year only.

†Model 1, with further adjustment for maternal age at pregnancy, maternal height, birth order number, family size, birth month, maternal education rural/urban residence and household wealth. $\ddagger$ Model 2, with further adjustment for gross domestic product (GDP) per capita purchasing power parity, health expenditure per capita, health expenditure as a percentage of GDP, female labour force participation and per cent living in urban environments. 
Table 5 Sensitivity analyses results

Effect estimate $(95 \% \mathrm{Cl})$

\begin{tabular}{|c|c|}
\hline \multicolumn{2}{|l|}{ Lead and lag effects* } \\
\hline Lead $t+2$ & 0.08 (0.00 to 0.12$)$ \\
\hline Lead $t+1$ & 0.08 (0.00 to 0.20$)$ \\
\hline Concurrent t & $0.08(-0.04$ to 0.24$)$ \\
\hline Lagged t-1 (main analysis) & $-0.08(-0.20$ to 0.04$)$ \\
\hline Lagged t-2 & $-0.08(-0.24$ to 0.04$)$ \\
\hline \multicolumn{2}{|l|}{ Additional sensitivity analyses } \\
\hline Restrict to under age 3 only & $0.06(-0.05$ to 0.17$)$ \\
\hline Using stunting indicator & $-0.01(-0.04$ to 0.07$)$ \\
\hline $\begin{array}{l}\text { Using maternity leave } \\
\text { full-time equivalent as the } \\
\text { exposure }\end{array}$ & $-0.02(-0.12$ to 0.07$)$ \\
\hline
\end{tabular}

*t refers to the child's year of birth. For example, $t+1$ means the exposure assigned to the subject was the legislated maternity leave in the year after the child's birth. The main exposure was $t-1$.

did not alter our conclusions (see online supplementary file 2: additional sensitivity analyses).

\section{DISCUSSION}

We found limited evidence that extending legislated paid maternity leave from an average of 8.6 to 14.0 weeks increases young children's height-for-age z scores in low-income and middle-income countries. Our findings are in contrast to those from studies of the effect of paid maternity leave on outcomes measured closer to birth, but in line with some other studies of longer term child health outcomes in higher income settings. ${ }^{28} 29$ This study was conducted in the context of a strong increase in child height-for-age $\mathrm{z}$ scores across all countries between 1996 and 2013.

Other work found that increased paid maternity leave was associated with lower infant mortality ${ }^{30}$ and increased vaccination uptake ${ }^{15}$ in low-income and middle-income countries, which are outcomes measured closer to birth. The difference in our findings could be a result of later exposures over-riding earlier benefits of paid maternity leave for children, so that effects attenuate or disappear over time. Further, the mechanisms linking maternity leave to child growth are likely not the same as for infant mortality and vaccination uptake. For instance, vaccination uptake often depends on reaching clinics, which may not be enabled by maternity leave. Finally, on average the paid maternity leave durations in our study were less than 6 months, which is too short to enable mothers to breast feed exclusively for 6 months. ${ }^{31}$ Combined with lowered income during leave, these policies may not allow parents to address adequate water, sanitation and dietary needs. ${ }^{32}$

The strong increasing trend in height-for-age $\mathrm{z}$ scores across the board could also make isolating the independent effect of maternity policies difficult. In both treated and control groups, we observed a marked increase in height-for-age $\mathrm{z}$ scores over the study period, which could overshadow any modest effect of paid maternity leave. Positive trends in child heightfor-age z scores between 1990 and 2010 are consistently observed,${ }^{33-35}$ but they have not generally been explained. Macro forces such as improved income and healthcare access may have driven the observed shifts in the population distribution of height-for-age $\mathrm{z}$ scores ${ }^{34}$ although the weak association between per-head GDP and stunting outcomes also suggests the need for targeted programmes. ${ }^{36}$ Maternity leave policies are a national approach, but may not be designed to reach the informal economy, which limits accessibility to people with particularly poor outcomes. This potential gap suggests a need to study maternity leave policies' specific formulation and their effects in combination with other drivers.

At the same time, across countries (including in Europe), height-for-age $\mathrm{z}$ score is already below or just hovers the standard mean of 0 at birth, and continues to falter everywhere until around 24 months of age, suggesting some intrauterine programming. ${ }^{37}$ The rate of decline in height-for-age $\mathrm{z}$ score could thus potentially represent an alternate important health outcome if repeat measurements on young children were available. Given the drawn-out timing of growth faltering, more work on the point at which intervention is effective might also reveal the relative importance of prenatal versus postnatal maternity leave, a distinction our policy database does not make.

Several caveats should be noted. Most of the maternity leave policies in our sample are relatively short. We would have been unable to capture any association if higher leave duration or pay is required to improve nutrition. To obtain unbiased results, our study design also assumes that no other factors changed over the same time period as the policy changes that we observed. Recommendations for mothers with HIV over the same time period to limit breast feeding, ${ }^{38}$ for instance, may have affected our results if the primary mechanism of impact is through breast feeding, and rates differed between control and treated countries. Second, the study design was meant to identify a mean population effect on nutrition outcomes, so it is possible that the policy did not reach enough women to observe a population effect. For instance, the policies may not be accessible to the most vulnerable women in the informal economy. However we adjusted for several characteristics that could predict women's uptake of maternity leave policies, as described in the Methods section.

\section{CONCLUSION}

We found little evidence that recent changes extending legislated paid maternity leave by an average of 5 weeks have affected young children's' mean height-for-age 
z scores in low-income and middle-income countries, controlling for social and economic factors. This study provides the first rigorous evidence on the impact of maternity leave on height-for-age z scores in low-income and middle-income countries. Future studies examining policies legislating longer maternity leave durations with strong coverage, alternative nutritional status indicators and combined policies and programmes may reveal further insight into this question.

Contributors $\mathrm{JH}$ led the initial development and framing of the global quantitative laws and policy databases on which this analysis is based. AN, JH and DJ conceptualised the idea. DJ performed the literature search, conducted the analyses and drafted the manuscript. SH and AN helped with the statistical analyses. All authors reviewed the manuscript for important intellectual content, contributed to the interpretation of results and revision of the manuscript, and approved the final draft

Funding All authors acknowledge funding from the Canadian Institutes of Health Research Operating Grant, Examining the impact of social policies on health equity (ROH-115209). AN is supported by the Canada Research Chairs Program. SH was supported by a Chercheur-boursier Junior 2 from le Fonds de recherche du Québec - Santé (FRQS)

\section{Competing interests None declared.}

Ethics approval IRB at McGill University.

Provenance and peer review Not commissioned; externally peer reviewed.

Data sharing statement Analyses utilised two sources of data, specifically: (1) height-for-age z score information collected from respondents surveyed as part of the Demographic and Health Surveys (DHS) (Table 1) and (2) measures of maternity leave policies. The DHS data are publicly available, but users must first register with the DHS program. Registration, which requires a summary of the proposed study and selection of country datasets, can be completed at: http://www. dhsprogram.com/data. Data on current maternity leave policies for each sampled country were provided by UCLA's World Legal Rights Data Centre (WoRLD) and then collected retrospectively to 1995 by McGill University's Maternal and Child Health Equity (MACHEquity) research program. The policy data are freely available through the website, www.machequity.com, without any restriction. The policy data, as well as the statistical code for producing the analytic dataset and replicating our results (given DHS data that must be downloaded from the DHS program), are also available with unrestricted access from the corresponding author's Dataverse: https://dataverse.harvard.edu/.

Open Access This is an Open Access article distributed in accordance with the Creative Commons Attribution Non Commercial (CC BY-NC 4.0) license, which permits others to distribute, remix, adapt, build upon this work non-commercially, and license their derivative works on different terms, provided the original work is properly cited and the use is non-commercial. See: http://creativecommons.org/ licenses/by-nc/4.0/

(C) Article author(s) (or their employer(s) unless otherwise stated in the text of the article) 2017. All rights reserved. No commercial use is permitted unless otherwise expressly granted.

\section{REFERENCES}

1. UNICEF-WHO-The World Bank. Levels \& Trends in Child Malnutrition. 2013 http://www.who.int/nutgrowthdb/summary_jme_ 2013.pdf

2. Alderman $\mathrm{H}$, Hoddinott $\mathrm{J}$, Kinsey B. Long term consequences of early childhood malnutrition. Oxf Econ Pap 2006;58:450-74.

3. Dewey KG, Begum K. Long-term consequences of stunting in early life. Matern Child Nutr 2011;7:5-18

4. Walker SP, Wachs TD, Gardner JM, Meeks Gardner J, et al. Child development: risk factors for adverse outcomes in developing countries. Lancet 2007;369:145-57.

5. Miller AC, Murray MB, Thomson DR, et al. How consistent are associations between stunting and child development? Evidence from a meta-analysis of associations between stunting and multidimensional child development in fifteen low- and middleincome countries. Public Health Nutr 2016;19.

6. Müller O, Krawinkel M. Malnutrition and health in developing countries. CMAJ 2005;173:279-86.
7. Smith LC, Ruel MT, Ndiaye A. Why Is Child Malnutrition Lower in Urban Than in Rural Areas? Evidence from 36 Developing Countries. World Dev 2005;33:1285-305.

8. Bhutta ZA, Das JK, Rizvi A, et al. Evidence-based interventions for improvement of maternal and child nutrition: what can be done and at what cost? Lancet 2013;382:452-77.

9. Pham VP, Nguyen VH, Salvignol B, et al. A six-month intervention with two different types of micronutrient-fortified complementary foods had distinct short- and long-term effects on linear and ponderal growth of Vietnamese infants. J Nutr 2012;142:1735-40.

10. Krebs NF, Mazariegos M, Chomba E, et al. Randomized controlled trial of meat compared with multimicronutrient-fortified cereal in infants and toddlers with high stunting rates in diverse settings. Am J Clin Nutr 2012;96:840-7.

11. Prudhon $\mathrm{C}$, Langendorf $\mathrm{C}$, Roederer $\mathrm{T}$, et al. Effect of ready-to-use foods for preventing child undernutrition in Niger: analysis of a prospective intervention study over 15 months of follow-up. Matern Child Nutr 2017:13:12236.

12. Negash C, Belachew T, Henry CJ, et al. Nutrition education and introduction of broad bean-based complementary food improves knowledge and dietary practices of caregivers and nutritional status of their young children in Hula, Ethiopia. Food Nutr Bull 2014;35:480-6.

13. Bassani DG, Arora P, Wazny K, et al. Financial incentives and coverage of child health interventions: a systematic review and meta-analysis. BMC Public Health 2013;13:S30.

14. Mirkovic KR, Perrine CG, Scanlon KS, et alBirth 2016.

15. Hajizadeh M, Heymann J, Strumpf E, et al. Paid maternity leave and childhood vaccination uptake: Longitudinal evidence from 20 lowand-middle-income countries. Soc Sci Med 2015;140:104-17.

16. Forero-Ramirez N, Gamboa LF, Bedi A, et al. Child malnutrition and prenatal care: evidence from three Latin American countries. Rev Panam Salud Publica 2014:35:163-71.

17. Ahmad R, Etp Y, Bujan S. Relationship between Types of Benefit (leave, loan and retirement plan) and Employees' Retention. International Journal of Education Research 2013;1.

18. Ruel MT, Alderman H; Maternal and Child Nutrition Study Group. Nutrition-sensitive interventions and programmes: how can they help to accelerate progress in improving maternal and child nutrition? Lancet 2013;382:536-51.

19. Corsi DJ, Neuman M, Finlay JE, Subramanian SV, et al. Demographic and health surveys: a profile. Int J Epidemiol 2012;41:1602-13.

20. World Health Organization. Child growth standards. $2017 \mathrm{http} / / /$ www.who.int/childgrowth/standards/chts Ihfa girls z/en/

21. Onis M. WHO Child Growth Standards based on length/height, weight and age. Acta paediatrica 2006;95:76-85

22. Heymann J, Raub A, Earle A. Creating and using new data sources to analyze the relationship between social policy and global health: the case of maternal leave. Public Health Rep 2011;126:127-34

23. Corsi DJ, Mejía-Guevara I, Subramanian SV. Risk factors for chronic undernutrition among children in India: Estimating relative importance, population attributable risk and fractions. Soc Sci Med 2016;157.

24. Fotso JC, Kuate-Defo B. Socioeconomic inequalities in early childhood malnutrition and morbidity: modification of the household-level effects by the community SES. Health Place 2005;11:205-25.

25. Bank W. World development indicators. $2014 \mathrm{http}: / /$ data.worldbank. org/data-catalog/world-development-indicators (accessed 26 Jan 2014)

26. Desa U. World Population Prospects, The 2012 Revision. New York: Department for Economic and Social Affairs, 2013.

27. International ICF. Demographic and Health Survey Sampling and Household Listing Manual. DHS M, ed. Calverton. Maryland: ICF International, 2012.

28. Baker M, Milligan K, employment M. Maternal employment, breastfeeding, and health: evidence from maternity leave mandates. $J$ Health Econ 2008;27:871-87.

29. Dustmann C, Schönberg U. Expansions in maternity leave coverage and children's long-term outcomes. J American Eco App Eco 2012;190:224.

30. Nandi A, Hajizadeh M, Harper S, et al. Increased duration of paid maternity leave lowers infant mortality in low- and middleincome Countries: a Quasi-experimental study. PLoS Med 2016;13:e1001985.

31. World Health Organization. Health topics: Breastfeeding. http://www. who.int/topics/breastfeeding/en/

32. Arimond M, Ruel MT. Dietary diversity is associated with child nutritional status: evidence from 11 demographic and health surveys. J Nutr 2004:134:2579-85. 
33. de Onis M, Blössner M, Borghi E. Prevalence and trends of stunting among pre-school children, 1990-2020. Public Health Nutr 2012;15:142-8.

34. Stevens GA, Finucane MM, Paciorek CJ, et al. Trends in mild, moderate, and severe stunting and underweight, and progress towards MDG 1 in 141 developing countries: a systematic analysis of population representative data. Lancet 2012;380:824-34.

35. Black RE, Victora CG, Walker SP, et al. Maternal and child undernutrition and overweight in low-income and middle-income countries. Lancet 2013;382:427-51.

36. Vollmer S, Harttgen K, Subramanyam MA, et al. Association between economic growth and early childhood undernutrition: evidence from 121 Demographic and Health Surveys from 36 low-income and middle-income countries. Lancet Glob Health 2014;2:e225-e234

37. Victora CG, de Onis M, Hallal PC, et al. Worldwide timing of growth faltering: revisiting implications for interventions. Pediatrics 2010;125:e473-e480.

38. Coutsoudis A. Breastfeeding and the HIV positive mother: the debate continues. Early Hum Dev 2005;81:87-93.

39. Filmer D, Pritchett L. The Effect of Household Wealth on Educational Attainment: Evidence from 35 Countries. Population and Development Review 1999;25:85-120.

40. Filmer D, Pritchett LH. Estimating wealth effects without expenditure data--or tears: an application to educational enrollments in states of India. Demography 2001;38:115-32. 